\title{
Ganho de peso de novilhas mestiças submetidas ou não à esterilização pela introdução intrauterina de esferas inoxidáveis e ao uso ou não de modificador orgânico
}

\author{
[Weight gain of crossbred heifers submitted or not to sterilization by intrauterine \\ stainless globes introduction and submitted or not to organic modifier use]

$$
\text { M.G. Abba }{ }^{1} \text {, M.A.R. Feliciano }{ }^{2 *} \text {, W.R.R. Vicente }{ }^{3}
$$ \\ ${ }^{1}$ Universidade de Marília - Marília, SP \\ ${ }^{2}$ Aluno de pós-graduação FCAV-UNESP - Jaboticabal, SP \\ ${ }^{3}$ Faculdade de Ciências Agrárias e Veterinárias - UNESP - Jaboticabal, SP
}

\begin{abstract}
RESUMO
Avaliou-se o ganho de peso de novilhas mestiças, 1/4 Simental e 3/4 Nelore, empregando-se o método experimental de esterilização, que consiste na introdução intrauterina de esferas inoxidáveis. Foram utilizadas 100 novilhas nulíparas, destinadas ao abate, com idades entre 12 e 24 meses e com média de peso de $275 \mathrm{~kg}$. Todos os animais receberam o mesmo manejo alimentar, em sistema de pastejo em Brachiaria brizantha, com água e sal mineral ad libitum, e pesagens a intervalos de 28 dias, obedecido o jejum prévio de 16 horas. Os animais foram distribuídos aleatoriamente em quatro grupos (G) experimentais: G1 - composto por 25 novilhas testemunhas; G2 - por 25 novilhas esterilizadas e aplicação de um modificador orgânico; G3 - por 25 novilhas esterilizadas; e G4 - por 25 novilhas não esterilizadas e aplicação de um modificador orgânico. Foram introduzidas 12 esferas de aço inoxidável, previamente esterilizadas, no útero de cada novilha. Houve maior ganho de peso total e diário entre os animais do G2, 140,50kg e 0,578g/dia vs 108,58kg e 0,447g/dia (G1), 103,73kg e 0,427g/dia (G3), $102,68 \mathrm{~kg}$ e $0,423 \mathrm{~g} / \mathrm{dia}(\mathrm{G} 4)$, respectivamente. Esta técnica pode ser recomendada aos criadores.
\end{abstract}

Palavras-chave: novilha, esterilização, ganho de peso, esferas inoxidáveis, modificador orgânico

\begin{abstract}
The weight gain in 1/4 Simental and 3/4 Nelore crossbred heifers was evaluated using an experimental method of castration, which consisted of stainless globes intra-uterine introduction. A total of 100 nulliparous heifers, destined to slaughter, aging from 12 to 24-months old and averaging $275 \mathrm{~kg}$ were used. The animals were randomly distributed in four experimental groups: G1: control; G2: sterilized heifers plus application of organic modifier; G3: sterilized heifers; and G4: non sterilized heifers plus application of organic modifier. It was concluded that G2 showed higher weight gain - 140,50kg and 0,578g/day vs 108,58kg and 0,447g/day (G1), 103,73kg and 0,427g/day (G3), 102,68kg and 0,423 g/day $(G 4)$. The sterilized heifers plus application of organic modifier is a method of castration recommended to the cattle farmers.
\end{abstract}

Keywords: heifer, sterilization, weight gain, stainless globes, organic modifier

\section{INTRODUÇÃO}

De acordo com Habermehl (1993), as fêmeas castradas são mais valorizadas, pois desenvolvem consideravelmente a porção anterior do corpo, apresentam melhor escore corporal e a mesma eficiência em converter nutrientes da dieta em ganho de peso que os machos castrados (Fernandes et al., 2008). Prado et al. (2000) relataram que o aparecimento do

Recebido em 13 de janeiro de 2009

Aceito em 31 de março de 2010

*Autor para correspondência (corresponding author)

E-mail: marcusfeliciano@yahoo.com.br 
estro pode prejudicar o desempenho das fêmeas em terminação, por isso pesquisadores e produtores procuram introduzir na criação métodos de fácil aplicação e de baixo risco que evitem o cio.

Marques et al. (2001), ao utilizarem a técnica de aplicação de esferas de chumbo no útero de novilhas, obtiveram melhor desempenho nos animais tratados em relação aos não tratados com essa técnica. Esse procedimento, em fêmeas destinadas ao abate, tem a finalidade de suprimir o estro e sua influência no ganho de peso e na qualidade de carcaça. Pascoal (1998), ao comparar o ganho de peso de novilhas não castradas, de novilhas castradas cirurgicamente e de novilhas implantadas com um corpo estranho de chumbo intrauterino, verificou que não houve diferença significativa entre os grupos estudados.

Os modificadores orgânicos estimulam o metabolismo animal, proporcionando maior desenvolvimento e ganho de peso. São poderosos reconstituintes orgânicos em situações de estresse e coadjuvantes em tratamentos póscirúrgicos e em doenças infecciosas e parasitárias. $\mathrm{O}$ uso de modificadores orgânicos tem a finalidade de otimizar o aproveitamento de alimentos, principalmente os de alta densidade, para ruminantes criados em condições extensivas (Mattos et al., 1994). Junqueira e Mangerona (1996; 1997), ao trabalharem com bovinos confinados e em pasto, respectivamente, verificaram, em ambos os grupos, maior ganho de peso em animais que receberam modificador orgânico.

O objetivo deste trabalho foi avaliar o ganho de peso de novilhas mestiças, submetidas ou não à esterilização pela introdução intrauterina de esferas inoxidáveis.

\section{MATERIAL E MÉTODOS}

Foram utilizadas 100 novilhas nulíparas mestiças, 1/4 Simental e 3/4 Nelore, com idades entre 12 e 24 meses, destinadas ao abate. Os animais, selecionados após prévio exame clínico e submetidos à palpação retal para avaliação da sanidade reprodutiva, foram distribuídos aleatoriamente em quatro grupos (G) de tratamentos, ao acaso, com 25 repetições por tratamento. O G1 foi formado por 25 novilhas testemunhas (não esterilizadas); o $\mathrm{G} 2$ por 25 novilhas esterilizadas e aplicação de modificador orgânico (Leivas Leite ${ }^{\circledR}$ ); o G3 por 25 novilhas esterilizadas e o G4 por 25 novilhas não esterilizadas e aplicação de modificador orgânico (Leivas Leite ${ }^{\circledR}$ ).

Os animais foram alimentados em sistema extensivo, em pastagem formada de Brachiaria brizantha, manejada de modo a obter capim de qualidade uniforme durante o experimento. A suplementação mineral e a água foram oferecidas ad libidum.

Após a identificação e aferição do peso inicial de cada novilha, foram aplicadas 12 esferas de aço inoxidável em cada um dos animais do G2 e do G4. As esferas de aço inoxidável, com diâmetro de três milímetros, após esterilização (Solução de $\mathrm{Kylol}^{\circledR}$ ), foram introduzidas no corpo do útero, usando o aplicador universal de inseminação artificial.

As pesagens de todos os animais foram realizadas em balança eletrônica, com capacidade para $1500 \mathrm{~kg}$ e precisão de $0,1 \mathrm{~kg}$, de 28 em 28 dias, com jejum prévio de 16 horas, para observação da variação de peso. Os animais também foram pesados um dia antes do abate, para obtenção do peso corpóreo ao abate.

A análise estatística foi realizada pelo método dos quadrados mínimos, utilizando o procedimento GLM do SPSS 13.0. Foram obtidos os valores médios e os desvios-padrão das variáveis paramétricas e procedeu-se à análise de variância e comparação entre médias pelo teste Tukey, para os grupos com variâncias homogêneas. A homogeneidade das variâncias, quando da comparação entre os grupos, foi verificada pelo teste de Levine (Banzatto e Kronka, 2006). Adotou-se, em todos os testes, o nível de significância de $5 \%$ de probabilidade, para rejeição da hipótese de nulidade.

\section{RESULTADOS E DISCUSSÃO}

Os animais do G2 estavam mais pesados aos 243 dias, e o ganho em peso diário foi maior $(\mathrm{P}<0,05)$ que os dos G1, G3 e G4 (Tab. 1). 
Tabela 1. Valores médios do peso inicial, aos 243 dias $(\mathrm{kg})$, ganho de peso total e ganho de peso diário (g/dia) de novilhas, segundo o grupo $(\mathrm{n}=25)$ de tratamento

\begin{tabular}{ccccc} 
Grupo $^{1}$ & Peso inicial & $\begin{array}{c}\text { Peso aos } 243 \\
\text { dias }\end{array}$ & Ganho de peso total & Ganho de peso (g/dia) \\
\hline G1 & $275,88 \mathrm{a}$ & $384,46 \mathrm{a}$ & $108,58 \mathrm{a}$ & $0,447 \mathrm{a}$ \\
G2 & $275,13 \mathrm{a}$ & $414,46 \mathrm{~b}$ & $140,50 \mathrm{~b}$ & $0,578 \mathrm{~b}$ \\
G3 & $275,36 \mathrm{a}$ & $379,08 \mathrm{a}$ & $103,73 \mathrm{a}$ & $0,427 \mathrm{a}$ \\
G4 & $275,40 \mathrm{a}$ & $378,08 \mathrm{a}$ & $102,68 \mathrm{a}$ & $0,423 \mathrm{a}$ \\
\hline
\end{tabular}

Tratamentos: G1= controle; G2= esterilização mais modificador orgânico; G3= esterilização; G4= modificador orgânico.

${ }^{1}$ Teste de Levine para a homogeneidade das variâncias nos momentos inicial $(\mathrm{P}=0,926)$, aos 243 dias $(\mathrm{P}=0,979)$ e para o ganho de peso $(\mathrm{P}=0,619)$.

Médias seguidas de letras distintas na coluna diferem entre si pelo teste Tukey $(\mathrm{P}<0,05)$.

O emprego de esferas intrauterinas para a esterilização indicou resultados positivos no ganho de peso de novilhas somente com o uso de modificador orgânico. Os resultados observados para os grupos G1, G3 e G4 foram semelhantes aos obtidos por Pascoal (1998) e por Silva et al. (2005). Esses autores concluíram que a castração de novilhas, bem como a implantação de dispositivos intrauterinos, não promoveria ganho de peso ao serem comparadas com novilhas inteiras. Sob esse prisma, permite-se destacar, ainda, a questão da importância de se utilizar algum método de esterilização em novilhas púberes, pois, segundo Shanbacher (1984), a falta de hormônios ovarianos, os quais são esteroides anabolizantes, é fator responsável pelo decréscimo no ganho de peso de novilhas castradas. Nesse sentido, uma forma de eliminar o estro com a manutenção dos ovários e, consequentemente, dos hormônios ovarianos é a utilização de um dispositivo intrauterino como método anticoncepcional, como as esferas de aço.

Uma possível explicação para o melhor desempenho somente de animais do G2 poderia estar ligada aos aspectos nutricionais envolvidos neste experimento. $\mathrm{O}$ manejo alimentar consistiu em forrageamento em um sistema extensivo em pasto, formado por Brachiaria brizantha, e suplementado com sal mineral, desse modo, pode-se inferir que o baixo valor nutricional da dieta tenha contribuído para o desempenho de produção, bem abaixo do esperado. Tal consideração evidencia-se quando os resultados do presente experimento são comparados aos obtidos por Turin et al. (1997), que trabalharam com novilhas com peso inicial similar, em sistema de confinamento, e constataram ganho de peso diário mais alto para as novilhas submetidas ao implante que para as novilhascontrole. Assim, pode-se supor que o possível ganho adicional, que poderia advir da utilização da técnica de implante de esferas intrauterinas, foi neutralizado pelo deficiente aporte nutricional, e somente a aplicação do modificador orgânico associada a essa técnica permitiu evidenciar a provável vantagem decorrente da implantação de esferas intrauterinas. Tal raciocínio encontra respaldo na constatação de Mattos et al. (1994), ao afirmarem que o uso de modificadores orgânicos otimizaria a utilização de alimentos na dieta de ruminantes em condições de criação extensiva.

Warwick et al. (1970) relataram que os animais não castrados apresentam taxa de ganho de peso corpóreo mais alta que os castrados. Em razão dessas considerações, acredita-se ser viável a utilização da metodologia proposta no presente trabalho, em novilhas, visando à melhora no desempenho de produção, desde que suplementadas com aporte nutricional ou, ainda, com o uso de modificador orgânico associado a essa técnica.

\section{CONCLUSÕES}

Pelo fato de ter havido maior ganho de peso em novilhas esterilizadas com esferas inoxidáveis associada à aplicação de modificador orgânico, recomenda-se essa técnica aos produtores.

\section{REFERÊNCIAS BIBLIOGRÁFICAS}

BANZATTO, D.A.; KRONKA, S.N. Experimentação Agrícola. 4.ed. Jaboticabal: FUNEP, 2006. 237p. 
FERNANDES, A.R.M.; SAMPAIO, A.A.M.; HENRIQUE, W. et al. Características da carcaça e da carne de bovinos sob diferentes dietas, em confinamento. Arq. Bras. Med. Vet. Zootec., v.60, p.139-147, 2008.

HABERMEHL, N.L. Heifer ovariectomy using the Willis spay instrument: technique, morbidity and mortality. Can. Vet. J., v.34, p.664-667, 1993.

JUNQUEIRA, O.M.; MANGERONA, A.M. Avaliação da eficácia do modificador orgânico Vallée, quanto ao parâmetro ganho de peso, em bovinos em sistema extensivo de criação, com repetição de dose. Hora Vet., v.15, p.4, 1997.

JUNQUEIRA, O.M.; MANGERONA, A.M. Desenvolvimento ponderal de bovinos confinados com modificador orgânico Vallée. Hora Vet., v.15, p.3, 1996.

MARQUES, J.A.; PRADO, I.N.; NASCIMENTO, W.G. Avaliação do desempenho de novilhas mestiças em diferentes condições reprodutivas confinadas. Rev. Bras. Zootec., v.34, p.2046-2056, 2001.

MATTOS, N.J.M.; BEZERRA, S.B.; DONATTI, F.C. et al. Utilização de modificadores orgânicos para ruminantes. Rio de Janeiro: UFRRJ, 1994.

PASCOAL, R.A.F. Efeito da castração $e$ introdução de chumbo intrauterino no ganho de peso de novilhas, 1998. 14f. Monografia (Curso de Zootecnia) - Universidade Estadual Paulista, Ilha Solteira, SP.
PRADO, I.N.; MARTINS, A.S.; ALCALDE, C.R. Desempenho de novilhas alimentadas com rações contendo milho ou casca de mandioca como fonte energética e farelo de algodão ou levedura como fonte proteica. Rev. Bras. Zootec., v.29, p. $278-287,2000$.

SCHANBACHER, B.D. Manipulation of endogenous and exogenous hormones for red meat production. J. Anim. Sci., v.59, p.16211630, 1984.

SILVA, H.L.; MERINHOS, M.L.G.; OLIVEIRA FILHO, B.D. et al. Efeitos da utilização do dispositivo intrauterino (DIU) sobre o ganho de peso e o rendimento de carcaça de novilhas Nelore destinadas ao abate. Cienc. Anim. Bras., v.6, p.95-103, 2005.

TURIN, E.M.; NAGLE, C.A.; LAHOZ, M. et al. Effects of a copper-bearing intrauterine device on the ovarian function, body weight gain and pregnancy rate of nulliparous heifers. Theriogenology, v.47, p.1327-1336, 1997.

WARWICK, E.J.; PUTNAM, P.A.; HINER, R.L. Effects of castration on performance and carcass characters of monozygotic bovine twins. J. Anim. Sci., v.31, p.296-301, 1970. 